\title{
Transaction
}

\section{Novel Fluorine-containing Poly(aryl ether amide)s derived from 2,3,4,5,6-Pentafluorobenzoic Acid}

\section{Ken Tanaka, Natsuko Sato, Shinichi Yamazaki, Kunio Kimura, and Yuhiko Yamashita}

Faculty of Environmental Science and Technology, Okayama University, 3-1-1 Tsushima-naka, Okayama 700-8530, Japan

\begin{abstract}
Various amide-containing aryl fluorides were synthesized from 2,3,4,5,6-pentafluorobenzoic acid, and novel fifteen AA-BB type and three AB type fluorine-containing poly(aryl ether amide)s (F-PEA) were obtained by nucleophilic aromatic substitution reaction. The synthesized aryl fluorides possessed several reactive carbons for the nucleophilic attack and cross-linking reaction occurred at $100^{\circ} \mathrm{C}$. Polymerizations were carried out at $80^{\circ} \mathrm{C}$ to avoid cross-linking and stopped just before gelation occurred. They had all para connected linear structures. The obtained F-PEAs showed excellent solubility and afforded tough transparent films by casting method. They also exhibited high $\mathrm{Tg}$ in the range of $179-273^{\circ} \mathrm{C}$ depending on the molecular structure. They showed good thermal stability, and even though F-PEAs contained amide linkage into the repeating unit of polymer molecule, they exhibited excellent hydrophobicity due to the incorporation of 2,3,5,6-tetrafluoro-1,4-phenylene moiety.
\end{abstract}

(Received December 25, 2005 ; Accepted February 10, 2006)

\section{Introduction}

High-performance fluorinated polymers have been receiving considerable attention as interesting advanced materials such as films, coatings for optical and microelectronics devices, gas separation membranes and so on.[1-3] The incorporation of fluorine atoms into polymer chains leads to polymers with increased solubility, flame resistance, thermal stability and glass transition temperature while also leading to decreased color, crystallinity, dielectric constant and moisture absorption. Owing these advantages, poly(aryl ether ketone)s (PEK) containing 1,1,1,3,3,3- hexafluoroisopropylidene moiety had been prepared and studied for use in aerospace and electronic applications.[4]

2,3,4,5,6-Pentafluorobenzoic acid (PFBA) is a valuable intermediate for pharmaceuticals, pesticides, perfumes, cosmetics and it is available as a commercial product. We have successfully prepared PEKs containing 2,3,5,6-tetrafluoro-1,4-phenylene moiety derived from PFBA (F-PEK) by aromatic nucleophilic substitution reaction.[5] The obtained F-PEKs showed excellent solubility into common organic solvents such as toluene and chloroform, and could be cast into tough transparent films. They also exhibited high $\mathrm{Tg}$ and outstanding thermal stability. Recently, various types of fluorine-containing aromatic polymers containing 2,3,5,6tetrafluoro-1,4-phenylene moiety have been synthesized for optical guide [6-9] and the demand for these fluorinecontaining aromatic polymers is increasing.

Poly(aryl ether amide)s had been widely prepared by nucleophilic aromatic substitution reaction between aryl fluorides containing amide linkage and bisphenols.[1012] Amide groups activated fluorine substituents for displacement by phenoxide nucleophiles. These polymers were claimed to be marginally soluble in polar aprotic solvents such as 1-methy-2-pyrrolidinone (NMP). These previous studies indicated that the nuclephilic aromatic substitution reaction was one of the suitable reactions for preparing poly(aryl ether amides)s and prompted us to synthesize fluorine-containing poly(aryl ether amide)s.

This paper describes our new finding on the preparation and characterization of novel fluorinecontaining poly(aryl ether amide)s (F-PEA) derived from PFBA. 


\section{Experimental}

\subsection{Materials}

PFBA was a gift from Nippon Shokubai Co. Ltd. 2,2 -Bis(4-hydroxyphenyl)-1,1,1,3,3,3-hexafluoropropane (6 FBA ), 2,2-bis ( 4-hydroxyphenyl) propane (BA), phenolphthalein (PP) and 4,4'-dihydroxydiphenyl ether (DPE), 4-aminophenol, 3-aminophenol and 2-aminophenol were obtained from Aldrich Co. Ltd. 9,9-Bis(4hydroxyphenyl)fluorene (HF) was obtained from TCI Co. Ltd. 1,4-Phenylene diamine (PPDA) was a gift from Taishin Kasei Kogyo Co. Ltd. 1,3-Phenylene diamine (MPDA), 4,4'-diaminodiphenyl ether (APE), N,Ndimethylacetoamide (DMAc) and NMP were purchased from Aldrich Co. Ltd.

\subsection{Monomer Synthesis}

1,4-Bis ( 2,3,4,5,6-pentafluorobenzamido ) benzene (1,4-PFBB): Into a $200 \mathrm{ml}$ three-neck flask equipped with an additional funnel and a nitrogen gas inlet tube were placed PPDA (3.6 g, $33 \mathrm{mmol})$, pyridine $(5.5 \mathrm{~g}, 66$ mmol) and $60 \mathrm{ml}$ of DMAc. 2,3,4,5,6-Pentafluorobenzoyl chloride (16.1 g, $66 \mathrm{mmol}$ ), which was synthesized from PFBA and thionyl chloride according to the previous procedure, ${ }^{5}$ was slowly added dropwise through an additional funnel at $0^{\circ} \mathrm{C}$. After the addition was complete, the reaction mixture was stirred for 2 hours at $5^{\circ} \mathrm{C}$ and for 24 hours at $25^{\circ} \mathrm{C}$. The reaction mixture was poured into water. The precipitates were collected by filtration and washed with water. After drying, recrystallization from ethanol with charcoal gave 1,4-PFBB (14.1 g, 81.2\% yield). Product characteristics were as follows. Tm : $286^{\circ} \mathrm{C}$. $\operatorname{IR}(\mathrm{KBr})\left(\mathrm{cm}^{-1}\right): 1671(\mathrm{C}=\mathrm{O}), 3074(\mathrm{~N}-\mathrm{H}) .{ }^{1} \mathrm{H}-$ NMR(ppm) : 11.06(s, NH, 2H), 7.69(s, aromatic, 4H). ${ }^{19} \mathrm{~F}-\mathrm{NMR}(\mathrm{ppm})$ : -136.3 (aromatic, $2 \mathrm{~F}$ ), -146.8(aromatic, 1F), -155.6(aromatic, 2F). Anal. Calcs. for $\mathrm{C}_{20} \mathrm{H}_{6} \mathrm{O}_{2} \mathrm{~N}_{2} \mathrm{~F}_{10}$ : $\mathrm{C}, 48.41 ; \mathrm{H}, 1.22$; N, 5.64. Found: C, 48.33; H, $1.58 ; \mathrm{N}, 5.61$.

1,3-Bis (2, 3, 4, 5, 6-pentafluorobenzamido) benzene (1,3-PFBB) and 4,4'-bis(2,3,4,5,6-pentafluorobenzamido) diphenyl ether (PFDE) were synthesized according to the procedure of 1,4-PFBB. Characteristics of 1,3-PFBB ; $\mathrm{Tm}: 264^{\circ} \mathrm{C}\left(\operatorname{ref}[13] \mathrm{m} . \mathrm{p} 261^{\circ} \mathrm{C}\right) . \operatorname{IR}(\mathrm{KBr})\left(\mathrm{cm}^{-1}\right): 1669$ $(\mathrm{C}=\mathrm{O}), 3167(\mathrm{~N}-\mathrm{H}) .{ }^{1} \mathrm{H}-\mathrm{NMR}(\mathrm{DMSO}, \delta \mathrm{ppm}): 11.09(\mathrm{~s}$, amide, $2 \mathrm{H}), 8.18(\mathrm{~s}$, aromatic, $1 \mathrm{H}), 7.47(\mathrm{t}, J=4.8 \mathrm{~Hz}$, aromatic, $1 \mathrm{H},), 7.45(\mathrm{~d}, J=6.0 \mathrm{~Hz}$, aromatic, $2 \mathrm{H}) .{ }^{19} \mathrm{~F}-$ $\mathrm{NMR}(\mathrm{MeOH}, \delta \mathrm{ppm}):-136.4($ aromatic, 2F), -147.0 (aromatic, 1F), -155.8(aromatic, 2F). Anal. Calcs. for $\mathrm{C}_{20}$ $\mathrm{H}_{6} \mathrm{O}_{2} \mathrm{~N}_{2} \mathrm{~F}_{10}$ : C, 48.41; H, 1.22; N, 5.64. Found: C, $48.29 ; \mathrm{H}, 1.47$; N, 5.66. Characteristics of PFDE;
$\mathrm{Tm}: 280^{\circ} \mathrm{C} . \quad \mathrm{FT}-\mathrm{IR}(\mathrm{KBr})\left(\mathrm{cm}^{-1}\right): \quad 1662(\mathrm{C}=\mathrm{O}), 3142(\mathrm{~N}-$ H). ${ }^{1} \mathrm{H}-\mathrm{NMR}(\mathrm{DMSO}, \delta \mathrm{ppm}): 11.01(\mathrm{~s}$, amide, $2 \mathrm{H}), 7.67$ (d, $J=9.0 \mathrm{~Hz}$, aromatic, $4 \mathrm{H}), 7.06(\mathrm{~d}, J=9.0 \mathrm{~Hz}$, aromatic, 4 H). ${ }^{19} \mathrm{~F}-\mathrm{NMR}(\mathrm{MeOH}, \delta \mathrm{ppm}):-133.3(2 \mathrm{~F}),-147.0(1 \mathrm{~F})$, 155.7(2F). Anal. Calcs. for $\mathrm{C}_{26} \mathrm{H}_{10} \mathrm{O}_{3} \mathrm{~N}_{2} \mathrm{~F}_{10}: \mathrm{C}, 53.08 ; \mathrm{H}$, $1.71 ; \mathrm{N}, 4.76$. Found: C, $52.95 ; \mathrm{H}, 1.98 ; \mathrm{N}, 4.75$. $N$-(2,3,4,5,6-Pentafluorobenzoyl)-4-aminophenol (4 AP) : Into a $200 \mathrm{ml}$ three-neck flask equipped with an additional funnel and a nitrogen gas inlet tube were placed 4-aminophenol (5.31 g, $49 \mathrm{mmol})$, pyridine (3.85 $\mathrm{g}, 49 \mathrm{mmol}$ ) and $60 \mathrm{ml}$ of DMAc. 2,3,4,5,6Pentafluorobenzoyl chloride (11.2 g, $49 \mathrm{mmol}$ ), which was synthesized from PFBA and thionyl chloride according to the previous procedure, ${ }^{5}$ was slowly added dropwise through an additional funnel at $0^{\circ} \mathrm{C}$. After the addition was complete, the reaction mixture was stirred for 2 hours at $5^{\circ} \mathrm{C}$. The reaction mixture was poured into water. The precipitates were collected by filtration and washed with water. After drying, recrystallization from methanol gave 4AP (10.0 g, 67.8\% yield). Product characteristics were as follows. Tm: $206^{\circ} \mathrm{C}$. $\mathrm{IR}(\mathrm{KBr})$ $\left(\mathrm{cm}^{-1}\right)$ : $1660(\mathrm{C}=\mathrm{O}) \quad 3290(\mathrm{~N}-\mathrm{H}) .{ }^{1} \mathrm{H}-\mathrm{NMR}(\delta \mathrm{ppm})$ (DMSO) : $7.42(\mathrm{~d}, J=8.7 \mathrm{~Hz}$, aromatic, $2 \mathrm{H}), 6.76(\mathrm{~d}, J=8.7$ $\mathrm{Hz}$, aromatic, 2H), 10.73(s, amide, $1 \mathrm{H}$ ), 9.40(s, hydroxy, 1H). ${ }^{19} \mathrm{~F}-\mathrm{NMR}(\mathrm{MeOH}, \delta \mathrm{ppm}):-136.8$ (aromatic, $\left.2 \mathrm{~F}\right)$, 147.9(aromatic, 1F), -156.4(aromatic, 2F). Anal. Calcs. for $\mathrm{C}_{13} \mathrm{H}_{6} \mathrm{O}_{2} \mathrm{NF}_{5}$ : C, $51.50 ; \mathrm{H}, 1.99 ; \mathrm{N}, 4.62$. Found : C, $51.67 ; \mathrm{H}, 2.27 ; \mathrm{N}, 4.61$.

$N$-(2,3,4,5,6-Pentafluorobenzoyl)-3-aminophenol (3 AP ) and $\quad N-(2,3,4,5,6$-pentafluorobenzoyl ) - 2aminophenol (2AP) were synthesized according to the procedure of 4AP. Characteristics of $3 \mathrm{AP}$; Tm : $221^{\circ} \mathrm{C}$. $\operatorname{IR}(\mathrm{KBr})\left(\mathrm{cm}^{-1}\right): \quad 1664(\mathrm{C}=\mathrm{O}), \quad 3307(\mathrm{~N}-\mathrm{H}) . \quad{ }^{1} \mathrm{H}-\mathrm{NMR}$ (DMSO, $\delta \mathrm{ppm}): 7.04(\mathrm{~d}, J=8.1 \mathrm{~Hz}$, aromatic, $1 \mathrm{H}), 7.26(\mathrm{~s}$, aromatic, $1 \mathrm{H}), 7.17(\mathrm{t}, J=8.0 \mathrm{~Hz}$, aromatic, $1 \mathrm{H}), 6.57(\mathrm{~d}, J=$ $8.0 \mathrm{~Hz}$, aromatic, $1 \mathrm{H}), 9.56(\mathrm{~s}$, hydroxy, $1 \mathrm{H}), 10.87(\mathrm{~s}$, amide, $1 \mathrm{H}) .{ }^{19} \mathrm{~F}-\mathrm{NMR}(\mathrm{MeOH}, \delta \mathrm{ppm})$ : -136.7(aromatic, 2F), -148.0(aromatic, 1F), -156.4(aromatic, 2F). Anal. Calcs. for $\mathrm{C}_{13} \mathrm{H}_{6} \mathrm{O}_{2} \mathrm{NF}_{5}$ : C, $51.50 ; \mathrm{H}, 1.99 ; \mathrm{N}, 4.62$. Found: C, $51.72 ; \mathrm{H}, 2.13 ; \mathrm{N}, 4.59$. Characteristics of 2AP ; Tm : $218^{\circ} \mathrm{C}$. IR $(\mathrm{KBr})\left(\mathrm{cm}^{-1}\right): 1670(\mathrm{C}=\mathrm{O}) 3218$ (N-H). $\quad{ }^{1} \mathrm{H}-\mathrm{NMR}(\mathrm{DMSO}, \delta \mathrm{ppm}): \quad 7.92(\mathrm{~d}, J=8.0 \mathrm{~Hz}$, aromatic, $1 \mathrm{H}), 7.04(\mathrm{t}, J=7.7 \mathrm{~Hz}$, aromatic, $1 \mathrm{H}), 6.94(\mathrm{~d}, J=$ $7.4 \mathrm{~Hz}$, aromatic, $1 \mathrm{H}), 6.84(\mathrm{t}, J=7.5 \mathrm{~Hz}$, aromatic, $1 \mathrm{H})$, 10.0(s, hydroxy, $1 \mathrm{H}), \quad 10.2(\mathrm{~s}$, amide, $1 \mathrm{H}) .{ }^{19} \mathrm{~F}-\mathrm{NMR}$ $(\mathrm{MeOH}, \delta \mathrm{ppm})$ : -136.9(aromatic, 2F), -148.1(aromatic, $1 \mathrm{~F}),-157.0$ (aromatic, $2 \mathrm{~F}$ ). Anal. Calcs. for $\mathrm{C}_{13} \mathrm{H}_{6} \mathrm{O}_{2} \mathrm{NF}_{5}$ : C, 51.50; H, 1.99; N, 4.62. Found: C, 51.64; H, $2.25 ; \mathrm{N}, 4.62$. 


\subsection{Polymerization}

Polymer codes in the present study are named by using the diamine moiety in aryl fluoride and the bisphenol for AA-BB type F-PEAs, and the aminophenol for AB type F-PEAs. For instance F-PEA(PPDA- 6FBA) stands for the polymer prepared from 1,4-PFBB, in which the diamine moiety is come from PPDA, and 6FBA. FPEA(4AP) stands for the polymer prepared from 4AP.

Polymerization of F-PEA(PPDA-6FBA) is described as a typical example. Into a $10 \mathrm{ml}$ flask equipped with a Dean-Stark trap, condenser, a magnet stirrer and nitrogen inlet tube were placed 6FBA $(0.2 \mathrm{~g}, 0.6 \mathrm{mmol})$, potassium carbonate $(0.09 \mathrm{~g}, 0.6 \mathrm{mmol}), 2 \mathrm{ml}$ of NMP and $2 \mathrm{ml}$ of toluene. The mixture was refluxed for 3 hours with eliminating by-produced water by azeotropic distillation and then toluene was distilled over. After being allowed to cool at $80^{\circ} \mathrm{C}, 1,4-\mathrm{PFBB}(0.3 \mathrm{~g}, 0.6 \mathrm{mmol})$ was added into the mixture. The solution was stirred at $80^{\circ} \mathrm{C}$ for 4 hours. The reaction mixture was allowed to cool to room temperature and poured into rapidly stirred water containing $1 \mathrm{wt} \%$ acetic acid. The precipitated polymer was isolated by filtration, washed twice with water. After drying, F-PEA(6FBA) was obtained as a powder $(0.45 \mathrm{~g}$, $95 \%$ yield).

\subsection{Characterization}

NMR spectra were recorded on AL300 SC-NMR, JEOL at $300 \mathrm{MHz}\left({ }^{1} \mathrm{H}\right), 298 \mathrm{MHz}\left({ }^{19} \mathrm{~F}\right) . \quad 4,4^{\prime}-$ Difluorobenzophenone was used as an internal standard for ${ }^{19} \mathrm{~F}-\mathrm{NMR}$ measurements. IR spectra were measured on JASCO FT/IR-410 spectrometer. Glass transition temperatures ( $\mathrm{Tg}$ ) and melting temperatures $(\mathrm{Tm})$ were measured by differential scanning calorimetry on PerkinElmer DSC 7 at a scanning rate of $20^{\circ} \mathrm{C} \cdot \mathrm{min}^{-1}$. Temperature and heat flow were calibrated using indium and zinc as the standards. Thermal stability was measured by thermogravimetric analysis on Perkin-Elmer TGA 7 at a heating rate of $20^{\circ} \mathrm{C} \cdot \mathrm{min}^{-1}$ in nitrogen atmosphere. Reduced viscosity ( $\eta \mathrm{sp} / \mathrm{C})$ was measured with an Ostwald-Fenske viscometer in DMAc at a concentration of $0.5 \mathrm{dL} \cdot \mathrm{g}^{-1}$ and $25^{\circ} \mathrm{C}$. Dynamic mechanical measurement was performed on Orientech Rheovibron DDV-II-EP at $110 \mathrm{~Hz}$ with a scanning rate of $2^{\circ} \mathrm{C} \cdot \mathrm{min}^{-1}$. Water contact angle of films was measured on Kyowa Kaimen Contact angle meter CA-D.

\section{Results and discussion}

Two different routes can be designed for the synthesis of F-PEAs, of which one is the making of ether linkage with aryl fluoride containing amide linkage and bisphenols, and another is that of amide linkage with dicarboxylic acid and diamine. The former route is more convenient to use PFBA as the starting material. It had been reported that the aryl fluoride containing an amide linkage reacted with phenoxides forming ether linkage without serious hydrolysis of amide linkage even at $180^{\circ} \mathrm{C} .[10-12]$ On the basis of this consideration, the nucleophilic substitution reaction was chosen for the synthesis of F-PEAs.

\subsection{Synthesis of AA-BB type F-PEAs}

Three different aryl fluorides containing amide linkage are synthesized as AA-BB type monomers from the corresponding diamines and 2,3,4,5,6pentafluorobenzoyl chloride converted from PFBA as illustrated in Scheme 1. As previously reported,[5] nucleophilic substitution polymerization of 4,4'-bis (2,3,4,5,6-pentafluorobenzoyl) diphenyl ether (BPDE) and bisphenols occurred at much lower temperature of $80^{\circ} \mathrm{C}$ in the presence of base. BPDE was highly susceptible to nucleophilic attack by bisphenoxide due to the electron-withdrawability of fluorine atoms and $\mathrm{C}=\mathrm{O}$. Aryl fluorides used in the present study are likely activated by amide $\mathrm{C}=\mathrm{O}$ and fluorine atoms like BPDE, and they may be polymerizable with bisphenols at lower temperature. The lower polymerization temperature is considerable benefit for the preparation of F-PEAs to avoid the hydrolysis of amide linkage during polymerization.

It has been reported that ${ }^{19} \mathrm{~F}$ spectroscopy can be used to probe the $\pi$-electron density at the actual site of reaction and it is a sensitive tool in regards to the nucleophilic aromatic substitution.[14-16] ${ }^{19} \mathrm{~F}$ chemical shift is corresponding to the $\pi$-electron density and the fluorine shifting lower field is more reactive for nucleophilic substitution due to higher electrophilicity.

The ${ }^{19} \mathrm{~F}$ chemical shifts of 1,4-PFBB are summarized in Table 1 with the results of BPDE. [5] The chemical shift of fluorine para position to an amide group of 1,4-PFBB is $-147.0 \mathrm{ppm}$ which is downfield from that of BPDE.

This result indicates that $1,4-\mathrm{PFBB}$ is activated in the ground state for the reactivity of the nuclephilic attach by a phenoxide due to an electron-withdrawing effect of an amide group on a 2,3,4,5,6-pentafluorophenyl ring. This activating amide group can also accept a negative charge lowering the activation energy for the displacement through a Meisenheimer complex. The chemical shift of fluorine para position to the amide group of 1,4-PFBB is upfield from that ortho positions.

This result suggests that the $\pi$-electron density at the ortho carbons is lower than the para carbon to the amide 


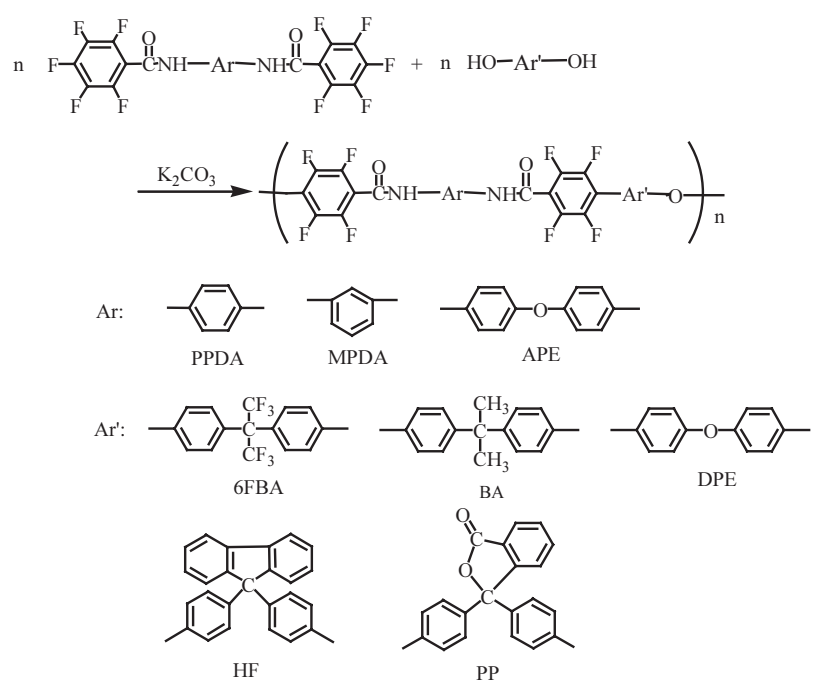

Scheme 1 Preparation of AA-BB type F-PEAs

Table $1{ }^{19}$ F-NMR chemical shifts of fluorine-containing various monomers

\begin{tabular}{cccc}
\hline \multirow{2}{*}{ Compound $^{\mathrm{a}}$} & \multicolumn{3}{c}{${ }^{19} \mathrm{~F}$ chemical shift $(\mathrm{ppm})^{\mathrm{b}}$} \\
\cline { 2 - 4 } & ortho & meta & para \\
\hline BPDE & -144.3 & -164.0 & -154.5 \\
1,4-PFBB & -136.2 & -155.7 & -147.0 \\
4AP & -136.8 & -156.5 & -148.0 \\
\hline
\end{tabular}

a: BPDE : 4,4' -bis (2,3,4,5,6-pentafluorobenzoyl) diphenyl ether, 1,4-PFBB : 1,4-bis(2,3,4,5,6- pentafluorobenzamido)benzene, 4AP : $\quad N-(2,3,4,5,6-$ Pentafluorobenzoyl)-4-aminophenol.

b: ${ }^{19} \mathrm{~F}$ chemical shifts were recorded in ppm relative to 101.1 ppm of 4,4'-difluorobenzophenone.

group and the ortho carbons have higher reactivity for the nucleophilic substitution reaction as the same as BPDE.

The optimization of polymerization conditions is necessary to prevent the reaction at ortho positions for preparing the linear polymers. Nucleophilic aromatic substitution polymerizations are typically performed in an aprotic polar solvent in the presence of base. Polymerizations were carried out in NMP. The solid compositions were $25 \%$. The potassium carbonate was used to convert the bisphenol into the more reactive anion. Toluene was used during the initial stages of the polymerizations to remove water generated by bisphenoxide formation as toluene azeotrope. In order to optimize the polymerization conditions, polymerization of 1,4-PFBB and 6FBA was examined at various temperatures. The polymerization at $100^{\circ} \mathrm{C}$ caused the gelation and the insoluble solids into DMAc were formed even after 1 hour. As aforesaid, the aryl fluorides possess

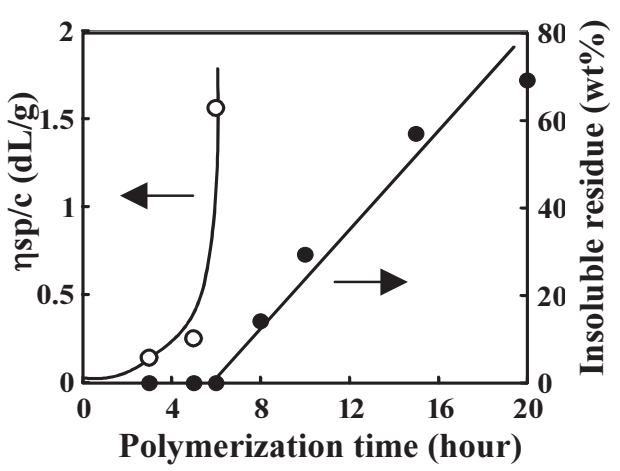

Figure. 11 Plots of viscosity and insoluble residue into DMAc of F-PEA(PPDA-6FBA) as a function of polymerization time.

Table $2{ }^{1}$ Results of polymerization

\begin{tabular}{lccc}
\hline \multicolumn{1}{c}{ Polymer code $^{\text {a }}$} & $\begin{array}{c}\text { Polymerization } \\
\text { time }\end{array}$ (hour) & $\begin{array}{c}\text { Yield } \\
(\%)\end{array}$ & $\begin{array}{c}\eta \mathrm{sp} / \mathrm{c}^{\mathrm{c}} \\
(\mathrm{dL} / \mathrm{g})\end{array}$ \\
\hline F-PEA(PPDA-6FBA) & 6 & 84 & 1.56 \\
F-PEAPPDA -HF) & 22 & 84 & 1.66 \\
F-PEA(PPDA -PP) & 5 & 91 & 2.00 \\
F-PEA(PPDA-BA) & 18 & 89 & 1.62 \\
F-PEA(PPDA-DPE) & 4 & 93 & 2.20 \\
F-PEA(MPDA-6FBA) & 8 & 82 & 1.05 \\
F-PEA(MPDA-HF) & 13 & 95 & 0.33 \\
F-PEA(MPDA-PP) & 6 & 87 & 0.85 \\
F-PEA(MPDA-BA) & 23 & 89 & 0.29 \\
F-PEA(MPDA-DPE) & 6 & 89 & 0.74 \\
F-PEA(APE-6FBA) & 4 & 90.9 & 0.33 \\
F-PEA(APE-HF) & 10 & 90 & 0.49 \\
F-PEA(APE-PP) & 5 & 92 & 0.38 \\
F-PEA(APE-BA) & 12 & 82 & 0.20 \\
F-PEA(APE-DPE) & 8 & 94 & 0.89 \\
F-PEA(4AP) & 4 & 89 & 0.86 \\
F-PEA(3AP) & 6 & 75 & 0.62 \\
F-PEA(2AP) & 20 & 75 & 0.63 \\
\hline
\end{tabular}

a: Polymer codes are shown in Scheme 2.

b: Polymerizations were carried out at $80^{\circ} \mathrm{C}$ and stopped just before the gelation started.

c: measured in DMAc at a concentration of $0.5 \mathrm{~g} \cdot \mathrm{dL}^{-1}$ and $25^{\circ} \mathrm{C}$.

totally six positions for nucleophilic substitution in which four positions are ortho and two positions are para to the amide linkage, and this caused the gelation by crosslinking. The polymerizations were carried out at $80^{\circ} \mathrm{C}$ to avoid the cross-linking reaction. Figure 1 shows the plots of reduced viscosity and the content of insoluble part of $F$ -PEA(PPDA-6FBA) in DMAc as a function of polymerization time. The values of $\eta \mathrm{sp} / \mathrm{c}$ increased with 
polymerization time and reached to $1.56 \mathrm{dL} \cdot \mathrm{g}^{-1}$ at 6 hours. The polymer was completely insoluble into DMAc up to 6 hours, whereas the content of insoluble part increased after 6 hours with time and the cross- linking reaction occurs gradually with time in the present polymerization. The chemical structure of the polymer prepared for 6 hours was confirmed by ${ }^{19} \mathrm{~F}$ and IR. In ${ }^{19} \mathrm{~F}-\mathrm{NMR}$ spectrum, three peaks were detected at $\delta$ of $-157.2,-145.0$ and -66.7 ppm corresponding to aromatic fluorines at ortho and meta position to the amide linkage, and 1,1,1,3,3,3hexafluoroisopropylidene moiety. The nucleophilic The nucleophilic aromatic substitution selectively occurred at the carbon para to the carbonyl groups in aryl fluoride until 6 hours and the resulting F-PEA(PPDA-6FBA) was para connected linear structure. IR shows that the amide $\mathrm{C}=\mathrm{O}$ band was clearly observed at $1674 \mathrm{~cm}^{-1} . \mathrm{C}=\mathrm{O}$ and $\mathrm{OH}$ bands of carboxylic acid did not appear which was generated by the hydrolysis of the amide linkage. These results indicate that the polymerization proceeded without the hydrolysis of amide linkage. The polymerizations of other monomers were also carried out at $80^{\circ} \mathrm{C}$ in the presence of potassium carbonate and stopped just before the gelation as shown in Table 2. The polymers were obtained with the yield of $81.5-95.4 \%$ and the values of $\eta \mathrm{sp} / \mathrm{c}$ were in the range of $0.20-2.20 \mathrm{dL} \cdot \mathrm{g}^{-1}$.

\subsection{Synthesis of A-B type F-PEAs}

Self-polymerizable monomers were designed and synthesized from corresponding aminophenols and 2,3,4,5,6-pentafluorobenzoyl chloride derived from PFBA as shown in Scheme 2. The ${ }^{19} \mathrm{~F}$ chemical shifts of 4AP are also presented in Table 1. The chemical shift of para position to the amide group of $4 \mathrm{AP}$ was $-148.0 \mathrm{ppm}$ which was downfield from that of BPDE, indicating the self-polymerizability of 4AP. Two ortho positions to an amide group also have higher reactivity than para position. First, the polymerization of $4 \mathrm{AP}$ was carried out at various temperatures under the similar condition of $\mathrm{AA}$ -BB type F-PEAs. The polymerization at $100^{\circ} \mathrm{C}$ caused the gelation and the insoluble solids into DMAc were formed even after $30 \mathrm{~min}$. Then, the polymerizations were carried out at $80^{\circ} \mathrm{C}$ to avoid the cross-linking reaction. The values of $\eta \mathrm{sp} / \mathrm{c}$ increased to $0.86 \mathrm{dL} \cdot \mathrm{g}^{-1}$ after 4 hours. The chemical structure of the polymer prepared for 6 hours was also confirmed by ${ }^{19} \mathrm{~F}$ and IR. In ${ }^{19} \mathrm{~F}-\mathrm{NMR}$ spectrum, two peaks were mainly detected at $\mathrm{d}$ of -136.5 and $-148.6 \mathrm{ppm}$ corresponding to aromatic fluorines at ortho and meta positiosn to the amide linkage. The resulting F-PEA(4AP) is mainly para connected linear structure. But the small peaks were observed at $\mathrm{d}$ of $-137.0,-146.8,-147.9,-154.9$, and -155.7 ppm due to

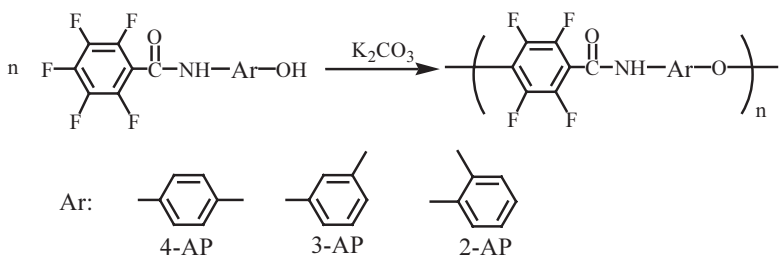

Scheme 2 Preparation of A-B type F-PEAs

the cross-linked structure. The polymer obtained for 4 hours was entirely soluble into DMAc but the crosslinking reaction slightly proceeded resulting in the formation of hyper-linked structure. IR showed that amide $\mathrm{C}=\mathrm{O}$ and $\mathrm{NH}$ band were clearly observed at 1675 and $3300 \mathrm{~cm}^{-1} . \quad \mathrm{C}=\mathrm{O}$ and $\mathrm{OH}$ bands of carboxylic acid did not appear which was generated by the hydrolysis of amide linkage. These results indicate that the polymerization occurred without the hydrolysis of amide linkage and the obtained polymer was confirmed as FPEA(4AP). The polymerizations of $3 \mathrm{AP}$ and $2 \mathrm{AP}$ were also carried out at $80^{\circ} \mathrm{C}$ and stopped before the gelation. F-PEA(3AP) and F-PEA(2AP) were obtained with the yield of 75.0 and $74.9 \%$ and the reduced viscosity of 0.62 and $0.63 \mathrm{dL} \cdot \mathrm{g}^{-1}$, respectively.

\subsection{Characterization}

Quantitative solubility of the F-PEAs was determined in excess of solvents. F-PEAs showed good solubility into THF besides aprotic polar solvents such as DMAc and NMP. Among them, F-PEA(2AP) was dissolved in chloroform due to the ortho catenation. Generally, aromatic polyamides are soluble only into the polar aprotic solvents due to the strong interaction between the polymer chains through hydrogen bonding of amide linkage. The incorporation of 2,3,5,6-tetrafluoro 1,4-phenylene moiety into the polymer structures enhances the solubility due to the lower interaction between polymer chains. Thermal properties are presented in Table 3. Tg of the obtained F-PEAs ranged from 179 to $274^{\circ} \mathrm{C}$, depending on the chemical structures. With respect to the structure of bisphenol of AA-BB type F-PEAs, there seems to be a tendency that $\mathrm{Tg}$ increases in the order of $\mathrm{HF}>\mathrm{PP}=\mathrm{BA}=6 \mathrm{FBA}>\mathrm{DPE}$. These tendencies are due to the presence of the bulky side groups in the polymer chain, being consistent with the previous work. $[1-3,5,17]$ With respect to that of diamine, it also increases in the order of PPDA $>$ MPDA $=$ APE. With respect to A-B type F-PEAs, the Tg's of F-PEA(4AP) and F-PEA(3AP) were $211^{\circ} \mathrm{C}$ and $210^{\circ} \mathrm{C}$ respectively, and they were ca. $30^{\circ} \mathrm{C}$ higher than $\mathrm{Tg}$ of F-PEA(2AP). Among all, F-PEA(PPDA-HF) processed the highest Tg of $274^{\circ} \mathrm{C}$. $\mathrm{Tg}$ is tunable by the combination of the used 


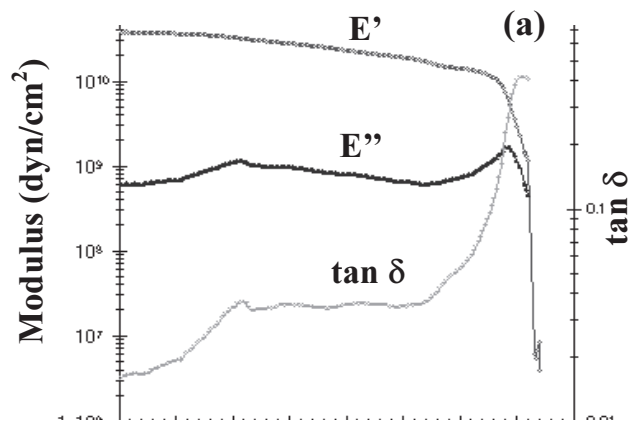

Temperature $\left({ }^{\circ} \mathrm{C}\right)$

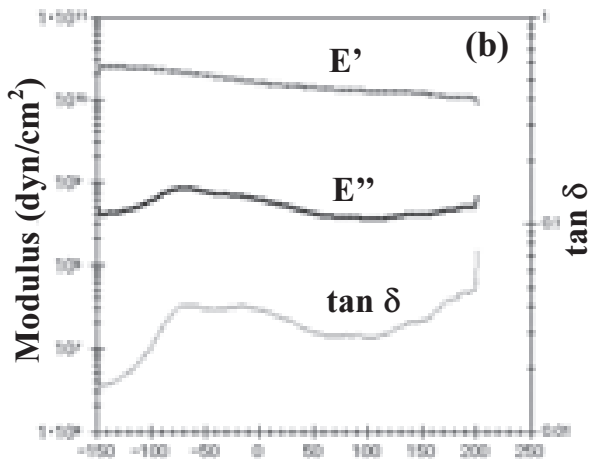

Temperature $\left({ }^{\circ} \mathrm{C}\right)$

Figure. 2 Dynamic mechanical scans of (a) F-PEA(PPDA-6FBA) and (b) F-PEA(4AP) films measured with a heating rate of $1^{\circ} \mathrm{C} \cdot \mathrm{min}^{-1}$ at frequency of $110 \mathrm{~Hz}$.

Table 3 Characterization of F-PEAs

\begin{tabular}{lccc}
\hline \multicolumn{1}{c}{ Polymer code ${ }^{\mathrm{a}}$} & $\begin{array}{c}\mathrm{Tg}^{\mathrm{b}} \\
\left({ }^{\circ} \mathrm{C}\right)\end{array}$ & $\begin{array}{c}10 \mathrm{wt}^{\circ} \% \\
\text { loss } \\
\left({ }^{\mathrm{o}} \mathrm{C}\right)\end{array}$ & $\begin{array}{c}\text { Water contact } \\
\text { angle (degree) }\end{array}$ \\
\hline F-PEA(PPDA-6FBA) & 210 & 394 & 98.1 \\
F-PEA(PPDA-HF) & 274 & 414 & 93.7 \\
F-PEA(PPDA-PP) & 227 & 404 & 91.4 \\
F-PEA(PPDA-BA) & 220 & 427 & 94.1 \\
F-PEA(PPDA-DPE) & 192 & 407 & 91.8 \\
F-PEA(MPDA-6FBA) & 222 & 413 & 94.1 \\
F-PEA(MPDA-HF) & 273 & 444 & 90.5 \\
F-PEA(MPDA-PP) & 215 & 409 & 88.2 \\
F-PEA(MPDA-BA) & 209 & 407 & 90.3 \\
F-PEA(MPDA-DPE) & 182 & 400 & 89.7 \\
F-PEA(APE-6FBA) & 220 & 425 & 93.7 \\
F-PEA(APE-HF) & 252 & 448 & 90.5 \\
F-PEA(APE-PP) & 221 & 429 & 90.6 \\
F-PEA(APE-BA) & 210 & 434 & 91.8 \\
F-PEA(APE-DPE) & 205 & 398 & 90.1 \\
F-PEA(4AP) & 211 & 444 & 91.1 \\
F-PEA(3AP) & 179 & 393 & 90.9 \\
F-PEA(2AP) & 210 & 496 & 90.5 \\
\hline
\end{tabular}

a: Polymer codes are shown in Scheme 2.

b: measured on DSC with a scanning rate of $20^{\circ} \mathrm{C} \cdot \mathrm{min}^{-1}$.

c: measured on TGA with a heating rate of $20^{\circ} \mathrm{C} \cdot \mathrm{min}^{-1}$.

bisphenol and diamine. These polymers did not exhibit Tm and they were amorphous polymers. Thermal stability was measured by TGA. Temperature of $10 \%$ weight loss in nitrogen atmosphere ranged from 393 to $496{ }^{\circ} \mathrm{C}$. From these results, they possess good thermal stability. Thermal stability is influenced by not only the molecular structure but also molecular weight. With respect to the molecular structure of AA-BB type F-PEAs, thermal stability is likely enhanced with the order of APE $>$ PPDA $=$ MPDA and 6 FBA $>$ HF $>$ PP $=$ DPE $>$ BA. Dynamic

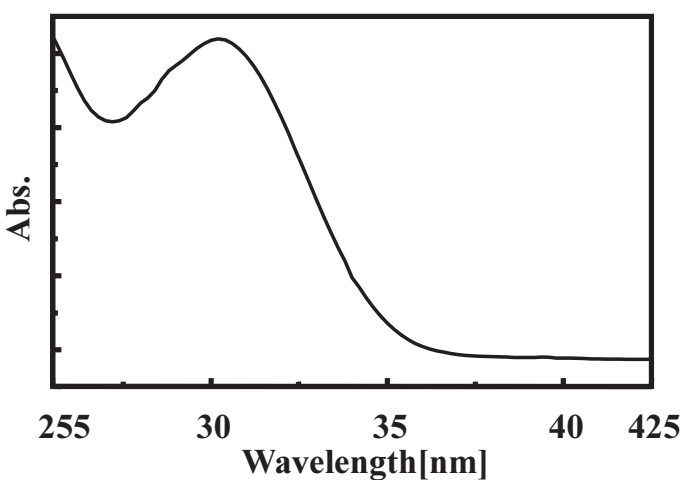

Figure. 3 Absorption spectra of F-PEA(PPDA- 6FBA) in tetrahydrofuran.

mechanical scans of F-PEA(PPDA-6FBA) and F-PEA(4 AP) films are shown in Figure 2. Dynamic modulus at $25^{\circ} \mathrm{C}$ was $1.75 \times 10^{10}$ dyne $\cdot \mathrm{cm}^{-2}$. The modulus decreases slightly with temperature and drops at ca. $170^{\circ} \mathrm{C}$ due to the a relaxation corresponding to glass transition. $\beta$ relaxation is observed at ca. $-50^{\circ} \mathrm{C}$ and this lower relaxation is attributed to the relaxation arising from the aryl ether group, called mechanical secondary relaxation or low temperature mechanical relaxatio.[17, 18] This relaxation is often observed in rigid aromatic polymers such as poly(aryl ether), poly(aryl sulfone) and polyarylate. [19] Absorption spectra of F-PEA(PPDA- 6 FBA) is shown as a typical example in Figure 3. This FPEA(PPDA-6FBA) film exhibited $\pi-\pi^{*}$ absorption at 298 $\mathrm{nm}$. The edge of this absorption was $350 \mathrm{~nm}$ and this film possesses excellent transparency. Water contact angle was measured on the surfaces of the films. The FPEA films were very hydrophobic due to the existence of fluorine atoms of which the contact angles were more than $88^{\circ}$, even though one amide linkage was contained in one repeating unit of polymer molecules. Among them, F-PEAs comprised of 6FBA exhibited excellent hydrophobicity due to $1,1,1,3,3,3-$ hexafluoro- 
isopropylidene moiety and F-PEA(PPDA- 6FBA) showed the most hydrophobicity, of which the contact angle was $98^{\circ}$.

\section{Conclusion}

Novel AA-BB type and AB type F-PEAs were prepared by using the nucleophilic aromatic substitution reaction of amide-containing aryl fluorides derived from PFBA and bisphenols, or self-polymerizable amidecontaining aryl fluorides at $80^{\circ} \mathrm{C}$ in the presence of potassium carbonate. They had all para connected linear structures confirmed by NMR. The obtained F-PEAs showed excellent solubility and afforded tough transparent films by casting method. They also exhibited high $\mathrm{Tg}$ in the range of $179-273^{\circ} \mathrm{C}$. It was likely that $\mathrm{Tg}$ depended on the molecular structure and it is tunable with the used monomers. They showed good thermal stability, and even though F-PEAs contained one amide linkage into the one repeating unit of polymer molecule, they exhibited excellent hydrophobicity due to the incorporation of 2,3,5,6-tetrafluoro-1,4-phenylene moiety.

\section{Acknowledgement}

The authors are very grateful to Nippon Shokubai Co. Ltd. and Taishin Kasei Kogyo Co. Ltd. for the gift of PFBA and PPDA. This study was also financially supported by Industrial Technology Research Grant Program in 2004 from New Energy and Industrial Technology Development Organization (NEDO) of Japan.

\section{References}

1. M. Bruma, J. W. Fitch, and P. E. Cassidy, J. Macromol. Sci.-Rev. Macromol. Chem. Phys., C36, 119(1996).

2. P. E. Cassidy, J. Macromol. Sci.-Rev. Macromol.
Chem.Phys., C34, 1 (1994).

3. P. E. Cassidy, T. M. Aminabhavi, and J. M. Farley, J. Macromol. Sci.-Rev. Macromol. Chem. Phys., C29, 365 (1989).

4. G. L. Tullos, and P. E. Cassidy, Macromolecules, 24, 6059 (1991).

5. K. Kimura, Y. Tabuchi, Y. Yamashita, P. E. Cassidy, J. W. Fitch, and Y. Okumura, Polymer for Advanced Technologie, 11, 757 (2000).

6. F. W. Mercer, M. M. Fone, V. N. Reddy, and A. A. Goodwin, Polymer, 38, 1989 (1997).

7. F. Liu, J. Ding, M. Li, M. Day, G. Robertson, and M. Zhou, Macromol. Rapid Commun, 23, 844 (2002).

8. D. Jianfu, L. Futian, L. Mei, D. Michael, and Z. Ming, J. Polym. Sci. Part A: Polym. Chem., 40, 4205 (2002).

9. J. P. Kim, J. W. Kang, J. J. Kim, and J. S. Lee, J. Polym. Sci. Part A : Polym. Chem., 41, 1497 (2003).

10. M. Lucas, and J. L. Hedrick, Polym. Bull., 28, 129 (1992).

11. M. Lucas, P. Brock, and J. L. Hedrick, J. Polym. Sci. Part A : Polym. Chem., 31, 2179 (1993).

12. J-B. Baek, and F. W. Harris, J. Polym. Sci. Part A : Polym. Chem., 41, 2374 (2003).

13. C. William, Brit. Patent 1075166, 6 (1967).

14. K. R. Carter, R. D. Miller, and J. L. Hedrick, Macromolecules, 26, 2209 (1993).

15. J. L. Hedrick, R. Twieg, T. Metray, and K. R. Carter, Macromolecules, 26, 4833 (1993).

16. J. L. Hedrick, and J. W. Labadie, Macromolecules, 23, 1561 (1990).

17. L. David, and S. Etienn, Macromolecule, 25, 4302 (1992).

18. L. M. Robeson, A. G. Farnham, J. E. McGrath, J. Appl. Polym. Symp., 26, 373 (1975).

19. T. Sasuga, N. Hayakawa, and K. Yoshida, J. Polym. Sci., Polym. Phys. Edn., 22, 529 (1984). 